\title{
Investigation of heat and mass transfer processes in the combustion chamber of industrial power plant boiler. Part 2. Distribution of concentrations of $\mathrm{O}_{2}, \mathrm{CO}, \mathrm{CO}_{2}, \mathrm{NO}$
}

\author{
A. Askarova ${ }^{a, b}$, V. Maximov ${ }^{a, *}$, S. Bolegenova ${ }^{a}$, S. Bolegenova ${ }^{a}$, \\ A. Yergaliyeva ${ }^{b}$, P. Šafařík ${ }^{c}$ \\ ${ }^{a}$ Research Institute of Experimental and Theoretical Physics, Tole bi 96 a, 050012, Almaty, Kazakhstan \\ ${ }^{b}$ Al-Farabi Kazakh National University, Faculty of Physics and Technology, al-Farabi 71, 050040, Almaty, Kazakhstan \\ ${ }^{c}$ Czech Technical University in Prague, Faculty of Mechanical Engineering, Technická 4, 16607 Prague, Czech Republic
}

Received 28 August 2017; accepted 9 November 2018

\begin{abstract}
In the present paper, a study of furnace processes in the combustion chamber of the real energy boiler BKZ-160 of Almaty TPP-3 (Kazakhstan) using three-dimensional modeling methods has been carried out. Calculations of the combustion chamber for flame combustion of pulverized coal have been performed. The main purpose of this paper was to study the effect of fractional fuel composition on the concentration characteristics of the combustion process. Numerical simulation was carried out with two models of coal particle size distribution: monodisperse fuel flame (coal particle size identical and equal to $60 \mu \mathrm{m}$ ) and a polydisperse fuel flame (coal particle diameter varies from 10 to $120 \mu \mathrm{m}$ ). The polydisperse distribution corresponds to the fractional distribution (percentage of total coal particles) calculated for this boiler: the first fraction $-10 \%$ with $d_{p}=10 \mu \mathrm{m} ; 20 \%$ with $d_{p}=30 \mu \mathrm{m}$; $40 \%$ with $d_{p}=60 \mu \mathrm{m} ; 20 \%$ with $d_{p}=100 \mu \mathrm{m} ; 10 \%$ with $d_{p}=120 \mu \mathrm{m}$. The numerical simulation results of the influence of the pulverized coal particle size composition on concentration characteristics of combustion process are presented. The distributions of oxidizer (oxygen) and combustion products $\left(\mathrm{NO}, \mathrm{CO}, \mathrm{CO}_{2}\right)$ are shown. Areas with the greatest concentration of gas products of burning are determined, regularities of formation of products and their concentration at the exit of fire chamber are also determined. The effect of fractional fuel composition on the obtained characteristics is sufficiently large, the empirical data obtained directly at TPP-3 show better convergence with the result of the computational experiment that confirms simultaneously the adequacy of the used physical and mathematical statement of the problem, as well as the validity of using the model of polyfractional distribution.
\end{abstract}

(c) 2018 University of West Bohemia. All rights reserved.

Keywords: combustion, modeling, concentration field, monodisperse pulverized coal flame, polydisperse pulverized coal flame

\section{Introduction}

Despite the great variety of alternative sources of energy, chemical energy obtained by way of combustion of power fuels occupies a disproportionately large part of the energy produced in the world [11]. This trend will occur in the near future, because it is convenient, energetically favorable and economical. Because of keen interest in hydrocarbon fuel, world reserves of oil and gas for the last centuries have been strongly depleted, production and use of coal - the long-term solution of "energy crisis", in connection with large world reserves of this fuel $[2,3,5]$.

The limited resources of fossil fuels dictate the need to search for more economical methods of its burning, and the scale of energy production is such that the problem of the formation of harmful substances during combustion comes to the fore [23]. The main pollutants from coal

${ }^{*}$ Corresponding author. Tel.: +7 70834622 08, e-mail: Valeriy.Maximov@kaznu.kz. https://doi.org/10.24132/acm.2018.396 
combustion are soot, sulfur, nitrogen and carbon oxides, which bring irreparable harm to the environment $[12,17]$. Today the world community is faced with a problem about pollution of Earth atmosphere due to the fact that environmentally harmful emissions occur.

First of all, for the solution of this problem it is necessary to study detailed process of fuel combustion that due to the complexity of physical and chemical reactions is still not fully understood. However, at the present stage of science and technology there is the opportunity to use numerical modeling techniques and numerical experiment for a wide range of tasks in the field of heat and mass transfer processes [4]. Computer simulation has become an indispensable method and an effective way to describe the heat and mass transfer processes in high-temperature and chemically reacting environments in the areas of real geometry of the flue combustion chambers [10].

In this paper process of coal combustion in the combustion chamber was investigated by the method of numerical simulation $[6-9,13,14]$. The aim of the study was to obtain the concentration characteristics of Ekibastuz coal combustion, the study of the basic laws of the distribution of concentration fields and their values in terms of the furnace combustion chamber. In the paper research was conducted with fuel of various dispersion and results of modeling the combustion of monodisperse and polydisperse flames are presented.

\section{Object and method of research}

For carrying out computational experiment the combustion chamber of the real power boiler BKZ-160 Almaty TPP-3 (Kazakhstan) was selected. The boiler BKZ-160 (Fig. 1) of drum-type furnace with dry slag removal has a calculated steam generating capacity $160 \mathrm{t} / \mathrm{h}$ at a pressure of $9.8 \mathrm{MPa}$ and a temperature of the superheated steam $540{ }^{\circ} \mathrm{C}$. Combustion chamber volume is $790 \mathrm{~m}^{3}$. On the sides of the combustion chamber there are four blocks direct flow slot burners (two burners in the block) which directed at a tangent to the circle with a diameter of one meter. Each burner has a fuel mixture channel and two secondary air channel, they are located from above and from below the channel of air-fuel mixture, and divided lined piers. The top and bottom burners are also divided by a pier. In the center of burners is located oil-fired nozzle for lighting and lighting of the flame. The performance of each of the eight coal-fired burner fuels is $4 \mathrm{t} / \mathrm{h}$. With a full description of the investigational boiler and its schema, the reader can familiarize themselves in article [15].

Numerical modeling was carried out on the basis of the solution of the nonlinear differential equations. It includes the solution of the equation of continuity and motion of a viscous medium, equations of heat diffusion and diffusion of components of the reacting mixture and the reaction products based on thermal radiation and multiphase media, equations of state, and chemical kinetics equations defining the intensity of nonlinear energy and matter. A detailed description can be found in $[19,22]$. To describe the motion and heat and mass transfer in the combustion of pulverized coal, the authors used the Euler method. This method uses the spatial equations of mass balance, momentum, gas component concentrations, and energy for the gas mixture, which can be written in a generalized form [22]

$$
\begin{aligned}
\frac{\partial(\rho \varphi)}{\partial t}= & -\frac{\partial\left(\rho u_{1} \varphi\right)}{\partial x_{1}}-\frac{\partial\left(\rho u_{2} \varphi\right)}{\partial x_{2}}-\frac{\partial\left(\rho u_{3} \varphi\right)}{\partial x_{3}}+ \\
& \frac{\partial}{\partial x_{1}}\left[\Gamma_{\varphi} \frac{\partial \varphi}{\partial x_{1}}\right]+\frac{\partial}{\partial x_{2}}\left[\Gamma_{\varphi} \frac{\partial \varphi}{\partial x_{2}}\right]+\frac{\partial}{\partial x_{3}}\left[\Gamma_{\varphi} \frac{\partial \varphi}{\partial x_{3}}\right]+S_{\varphi} .
\end{aligned}
$$

In this generalized equation: $\phi$ - the transport variable; $S_{\phi}$ - the source term, which is determined by the chemical kinetics of the process, nonlinear effects of thermal radiation, interphase 
interaction, as well as multistage chemical reactions; $\rho$ - density; $u_{1}, \ldots, u_{3}$ - velocity vector components; $x_{1}, \ldots, x_{3}$-spatial coordinates; $\Gamma_{\phi}$ - turbulent exchange coefficient.

The specified system of equations is solved numerically using the control volume method, which is described in detail in [22] and was subsequently used in carrying out computational experiments on burning of high-ash coal at Kazakhstan thermal power plants.

In this paper software package FLOREAN [18,19] for 3-D modeling of coal-dust combustion in furnaces of real-sized boilers was used. The FLOREAN program package for computations was developed at the Institute of Heat Engineering and Combustion of the Technical University, Braunschweig (Germany). 3D simulation in this program makes it possible to derive detailed information on the furnace performance, including fields of velocity, temperature, heat radiation, concentration distributions, etc., in the furnace axis and along the walls. The information derived during simulation is useful for estimation of combustion and for design of an optimum furnace for operating in industries. The application of FLOREAN is also useful for enhancement of combustion of various fuels in industrial boilers, optimization of operations, and minimization of pollutant emissions [16,20,21].

\section{The results of calculation}

To improve the environmental and energy performance of any thermal power plant and the complex as a whole, we need to learn how to significantly influence the processes of combustion of substances occurring in the combustion chambers. In this context, the numerical experiment on the combustion of pulverized coal, which was carried out by the authors of this article, is the most effective method of investigation.

Fig. 1 shows a general view of the combustion chamber BKZ-160 and its mesh into control volumes $(60 \times 72 \times 120)$ and aerodynamics of a stream of air-fuel mixture at tangential configuration of flames [15].

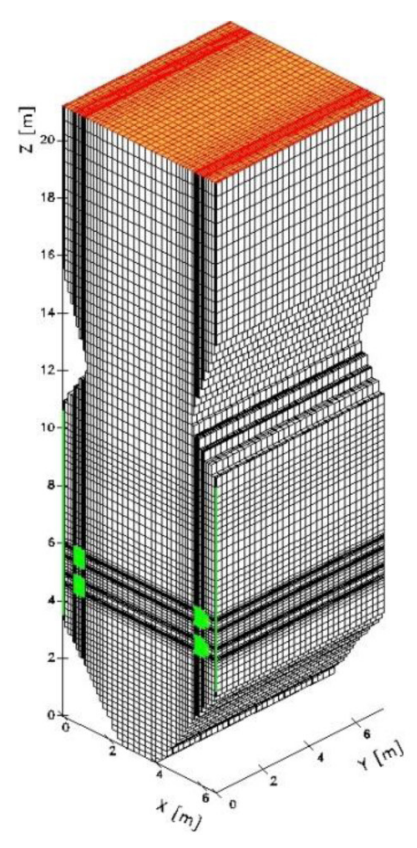

a)

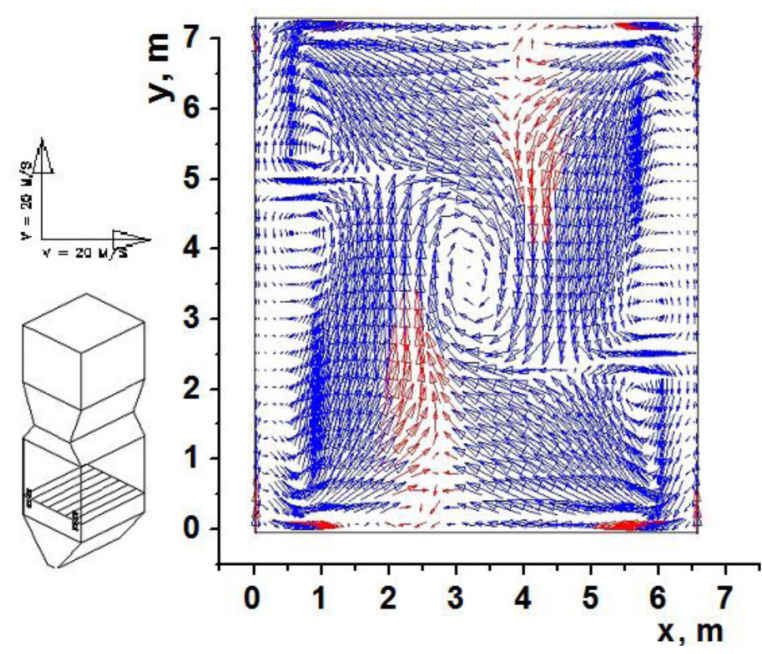

b)

Fig. 1. The combustion chamber of the boiler BKZ-160: a) general view of a computational mesh of the control volumes, b) flow field with the tangential feed of polydisperse coal dust 
Combustion of energy fuel is accompanied by the formation of harmful emissions, the amount of which in each case depends on the technology and regimes of burning coal dust, as well as on its composition. The most harmful substances that enter the atmosphere during combustion in the combustion chambers of pulverized coal are solids (ash, dust, soot particles), as well as gas emissions (oxides of nitrogen, carbon, sulfur, etc.).

To solve the problem of dust and gas emissions of air pollution, it is necessary to develop an environmentally "pure" energy fuel combustion technology. In this regard research of concentration characteristics of hazardous substances in products of burning is an actual task.

Since the concentration of carbon monoxide and carbon dioxide, and nitrogen oxides also depend directly on the concentration of oxygen in the combustion chamber, Figs. 2 and 3 show the distribution of oxygen in the central cross-section of researched combustion chamber, as well as two-dimensional distribution of oxygen concentration on its height.

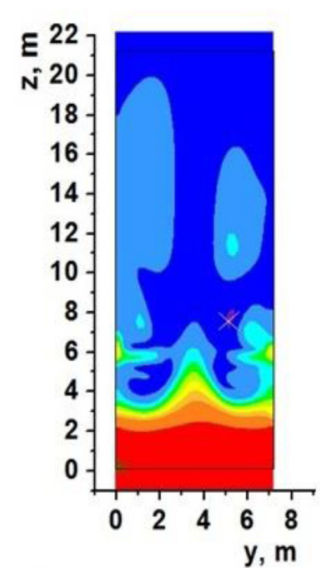

$\mathrm{O}_{2}, \mathrm{~kg} / \mathrm{kg}$

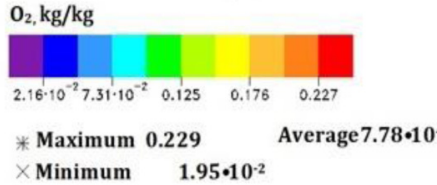

a) Monodisperse flame

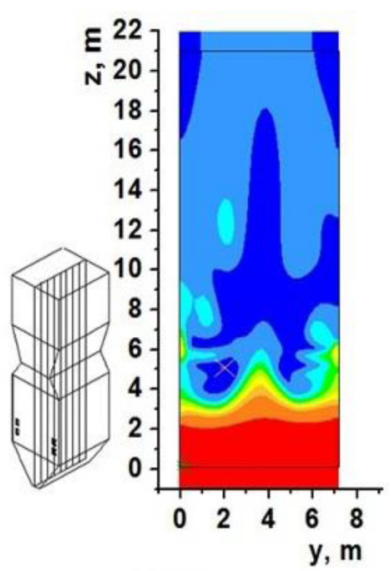

$\mathrm{O}_{2}, \mathrm{~kg} / \mathrm{kg}$

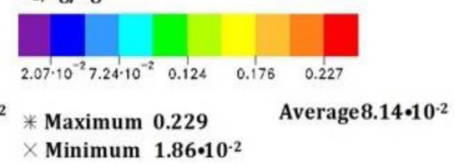

b) Polydisperse flame

Fig. 2. istribution of the oxygen $\mathrm{O}_{2}$ concentration in the longitudinal cross-section of the combustion chamber $(y=3.7 \mathrm{~m})$

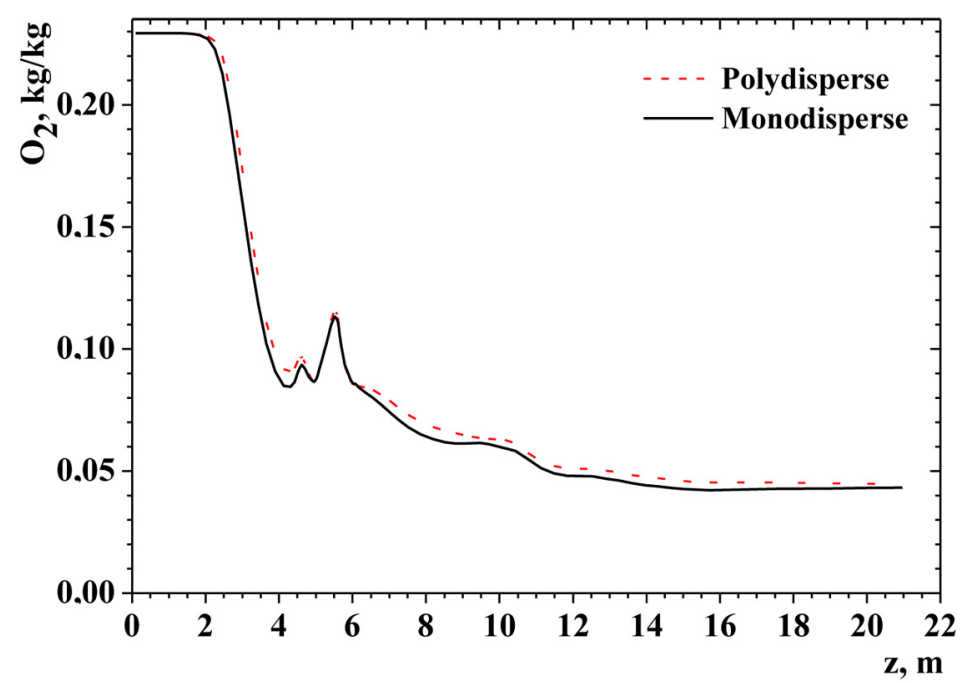

Fig. 3. Comparison of the average oxygen concentration values for poly- and monodisperse flame on height of the combustion chamber 
It should be noted that the distributions of all concentration characteristics are shown in comparison of burning monodisperse and polydisperse coal dust.

In the longitudinal section $(x=3.16 \mathrm{~m}$ ) of the combustion chamber the oxygen concentration distribution zone is clearly visible, it should be noted that the nature of the oxygen distributions of polydisperse and monodisperse flame differ. In the case of burning polydisperse pulverized coal zones the oxygen concentration has higher value and dominates in comparison with the burning monodisperse flame (Fig. 2). The average value of the oxygen concentration $\mathrm{O}_{2}$ in longitudinal section $(x=3.16 \mathrm{~m})$ for the polydisperse flame is $8.14 \cdot 10^{-2} \mathrm{~kg} / \mathrm{kg}$, for the monodisperse flame is $7.78 \cdot 10^{-2} \mathrm{~kg} / \mathrm{kg}$.

Analyzing Fig. 3 there is a uniform decline in oxygen concentration on height of the combustion chamber, result of its gradual burnout at the initial stage of combustion process. The peaks of oxygen $\mathrm{O}_{2}$ concentration in the arrangement of burners indicates oxidant feed point. It is clearly seen that the average oxygen concentration in combustion polydisperse dust takes large values in each section of the combustion chamber.

Figs. 4-6 and 8-9 show the distributions of the concentration of carbon oxides in the cases of combustion of polydisperse and monodisperse flame.

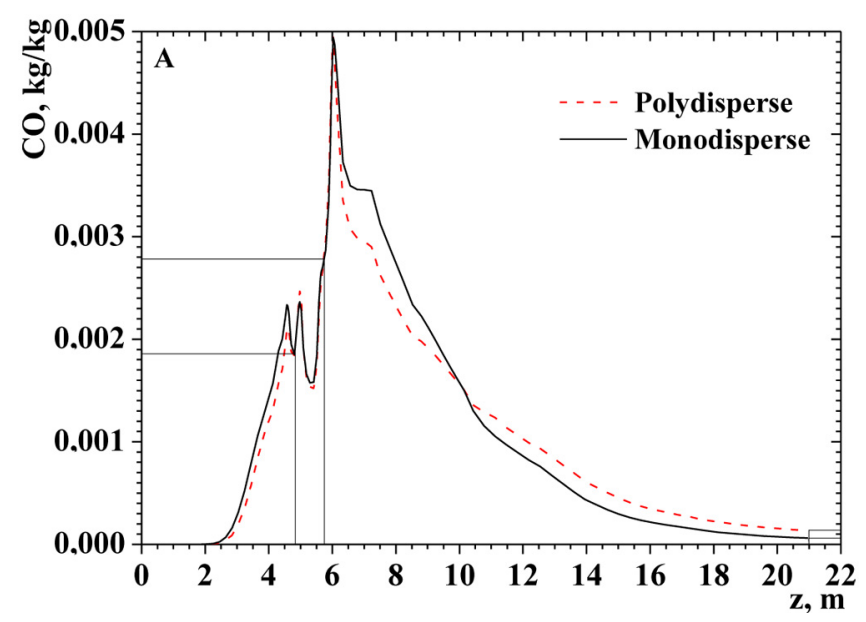

Fig. 4. Comparison of the average values of concentration $\mathrm{CO}$ for poly- and monodisperse flame on height of the combustion chamber

In the field of an arrangement of burners concentrations of poly- and monodisperse flame do not differ. The average value of the concentration of carbon monoxide for polydisperse flame in the first tier of burners $(z=4.81 \mathrm{~m})$ is $0.184 \cdot 10^{-2} \mathrm{~kg} / \mathrm{kg}$, for monodisperse is $0.185 \cdot 10^{-2} \mathrm{~kg} / \mathrm{kg}$, in the second tier $(z=5.79 \mathrm{~m})$ is $0.279 \cdot 10^{-2} \mathrm{~kg} / \mathrm{kg}$ both for poly- and for monodisperse flame (Fig. 4). In the area of active burning the concentration of carbon monoxide $\mathrm{CO}$ reaches the maximum value, chemical processes of formation of carbon monoxide $\mathrm{CO}$ fade to output from the combustion chamber, for polydisperse flame at the exit of the combustion chamber the mean value is $1.35 \cdot 10^{-4} \mathrm{~kg} / \mathrm{kg}$, for monodisperse is $0.61 \cdot 10^{-4} \mathrm{~kg} / \mathrm{kg}$.

Analyzing the Figs. 5 and 6 it can be argued, the nature and pattern of carbon monoxide CO and carbon dioxide $\mathrm{CO}_{2}$ are different from each other. Concentration of carbon oxide reaches area of the maximum values in a zone of active burning, unlike carbon dioxide which concentration increases as it moves out of the combustion chamber. 


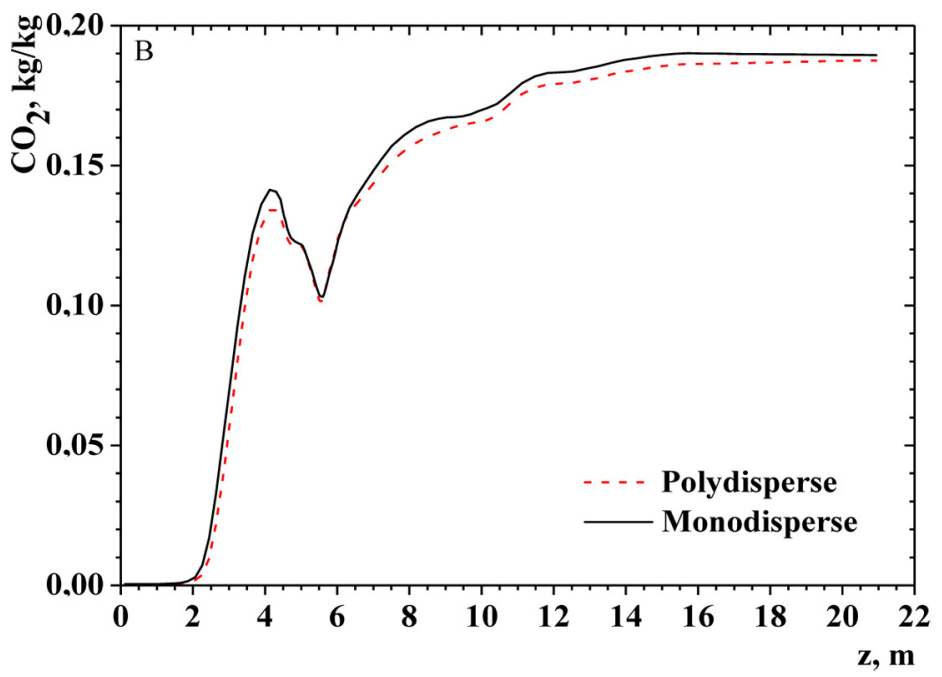

Fig. 5. Comparison of the average values of concentration $\mathrm{CO}_{2}$ for poly- and monodisperse flame on height of the combustion chamber

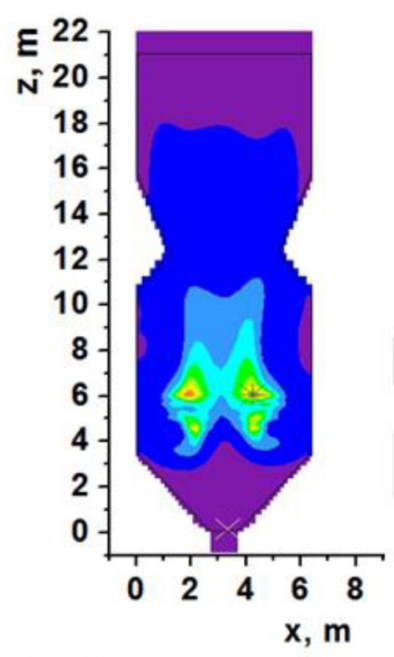

$\mathrm{CO}, \mathrm{kg} / \mathrm{kg}$

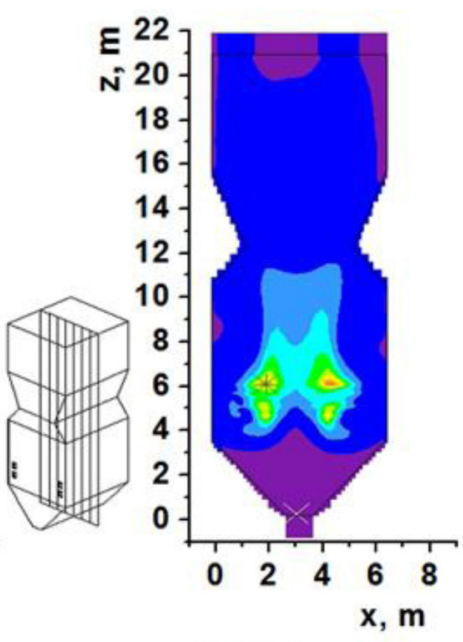

$\mathrm{CO}, \mathrm{kg} / \mathrm{kg}$

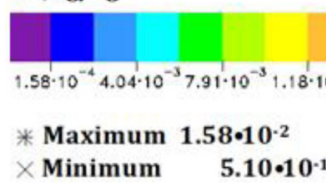

a) Monodisperse flame

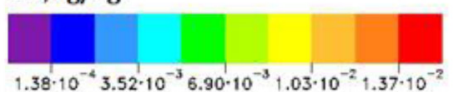

Average $1.21 \cdot 10^{-3} *$ Maximum $1.38 \cdot 10^{-2}$ Average $1.18 \cdot 10^{-3}$ Minimum 2.93 $10^{-11}$

b) Polydisperse flame

Fig. 6. Distribution of the carbon oxide concentration in the longitudinal cross-section of the furnace combustion chamber $(y=3.7 \mathrm{~m})$

Fig. 7 shows the experimental points obtained directly from measurements at the thermal power plant. This experiment was conducted during the commissioning of this boiler. The experimental data used in this article were obtained by burning polydisperse coal dust with a fineness of grinding equal to $R_{90}=15 \%$. During the experiment, Ekibastuz coal was burned with an ash content of $36.9 \%$ and a humidity of $6.5 \%$. It is confirmed that the numerical simulation results are in good agreement with the results of a natural experiment. It is leading to the conclusion of the applicability of the proposed physical-mathematical model of combustion processes, used in the present work. 


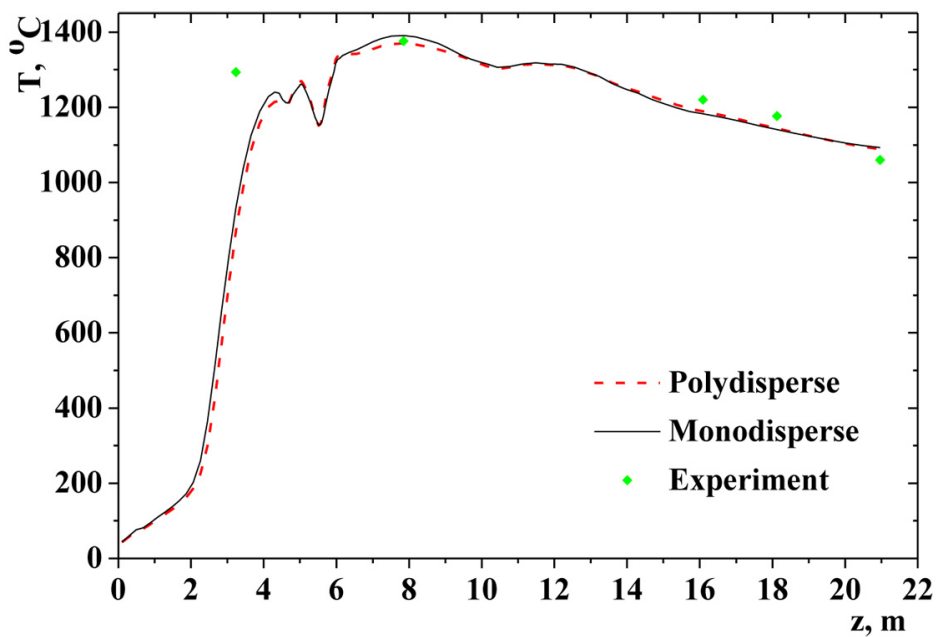

Fig. 7. Comparison of average temperature values for poly- and monodisperse flame on height of the combustion chamber and a comparison with the full-scale experiment $[1,15]$
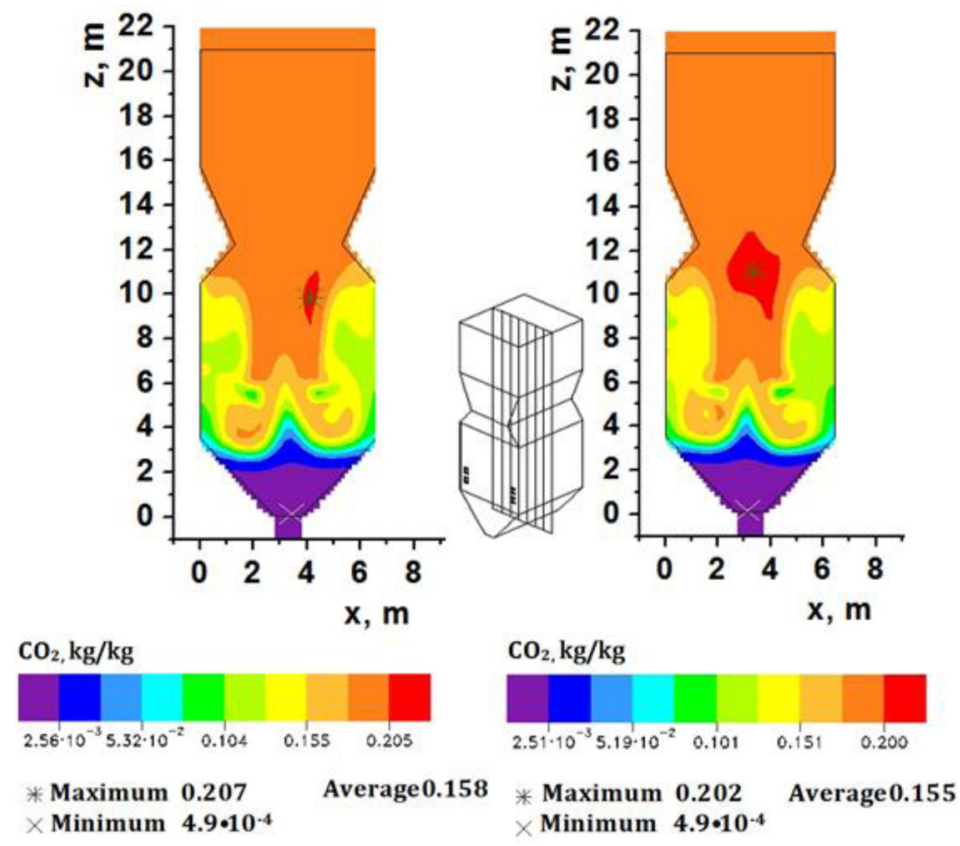

$\begin{array}{ll}\text { a) Monodisperse flame } & \text { b) Polydisperse flame }\end{array}$

Fig. 8. Distribution of carbon dioxide concentration in a longitudinal cross-section of the combustion chamber of the combustion $(y=3.7 \mathrm{~m})$

Nitrogen oxides are a result of the interaction of nitrogen with oxygen. These oxides are hazardous substances. About $40 \%$ of the total amount of nitrogen oxides emitted to the atmosphere accounted for thermal power plants. Formation of monoxide of nitrogen NO is $95-99 \%$, formation of toxic dioxide of nitrogen $\mathrm{NO}_{2}$ equal to $1-5 \%$ when burning fuel. To date, as a result of many studies generally recognized three mechanisms of nitrogen oxide: thermal oxidation of nitrogen in the air; air nitrogen oxidation with participation of reactions of pyrolysis of hydrocarbons (formation of "fast" nitrogen oxides); and oxidation of nitrogen contained in the fuel (fuel nitrogen oxides) [24, 25].

Distribution of average values of concentration of nitrogen oxide of poly-and monodisperse flame is shown in Figs. 10-12. 


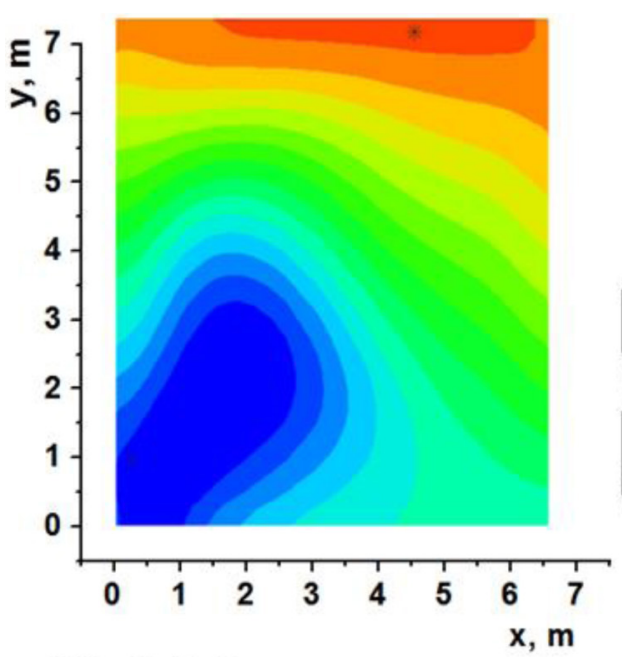

$\mathrm{CO}_{2}[\mathrm{~kg} / \mathrm{kg}]$

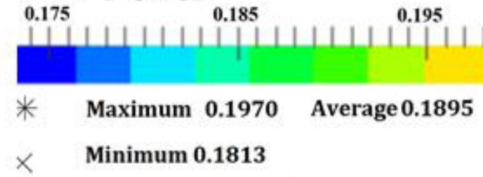

a) Monodisperse flame

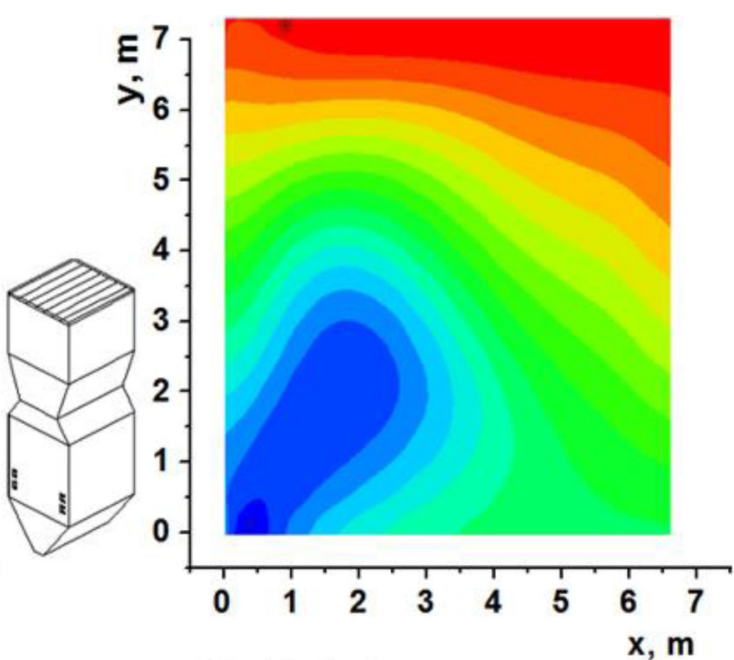

$\mathrm{CO}_{2}[\mathrm{~kg} / \mathrm{kg}]$

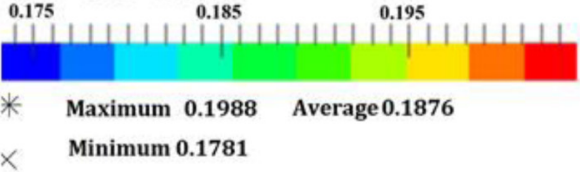

b) Polydisperse flame

Fig. 9. Distribution of carbon dioxide concentration in the cross-section $(z=20.96 \mathrm{~m})$ of the combustion chamber

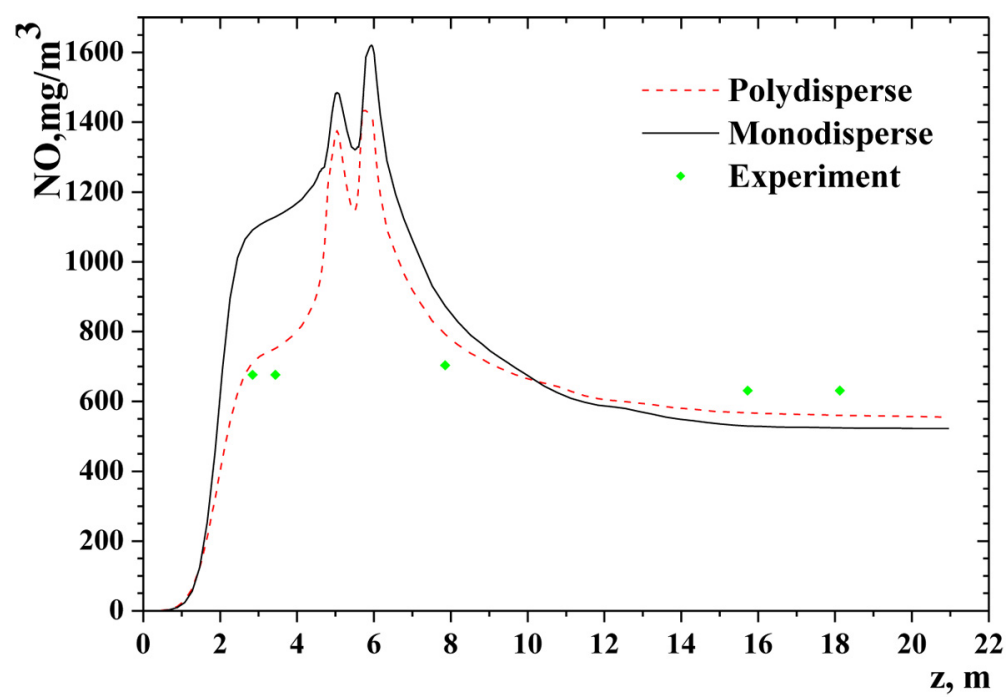

Fig. 10. Distribution of the average values of NO concentration of poly- and monodisperse flame and a comparison with the data of field experiment [1]

As seen from the pictures the most intensive gas generation of the main nitrogen-containing components comes in the field of distribution of streams from flame, where present in the maximum amount of fuel and oxidizer, which corresponds to the real picture of the process in the combustion chamber.

At the same time nature of distribution of concentration of nitrogen oxide is ambiguous that speaks about difficult nonlinear nature of this process. From the analysis of Figs. 7 and 10 it is possible to assume that in the field of active burning concentration of nitrogen oxide NO depends on value of temperature in this area that is connected with Zeldovich's mechanism (formation 


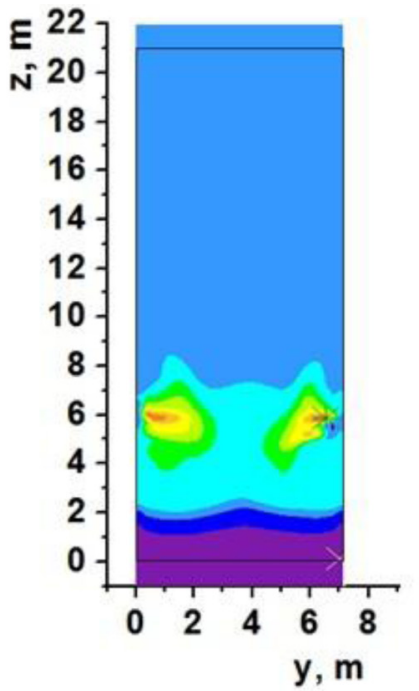

No, $\mathrm{mg} / \mathrm{m}^{3}$

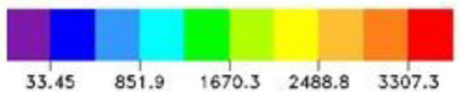

* Maximum 3340.7 Average 715.2 $\times$ Minimum $4.07 \cdot 10^{-2}$

a) Monodisperse flame

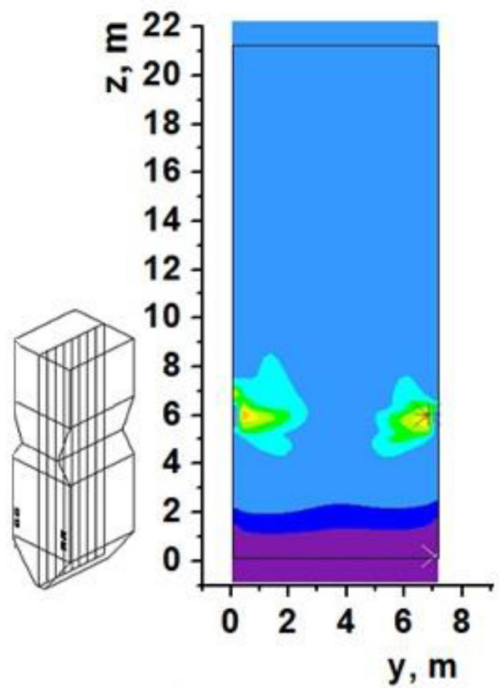

NO, $\mathrm{mg} / \mathrm{m}^{3}$

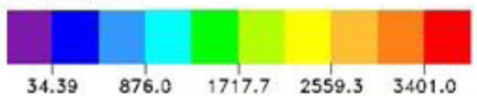

* Maximum 3435.3 Average612.0

$\times$ Minimum 4.01•10-2

b) Polydisperse flame

Fig. 11. Distribution of concentration of nitrogen oxide in a longitudinal cross-section of the combustion chamber $(x=3.16 \mathrm{~m})$

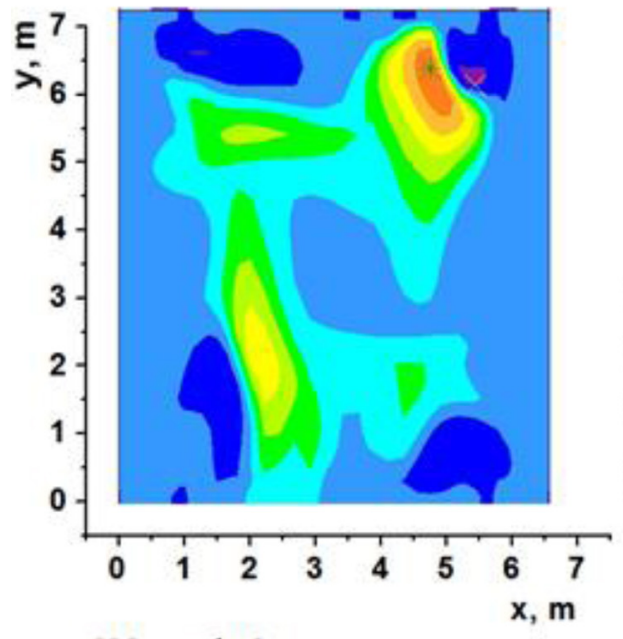

NO, $\mathrm{mg} / \mathrm{m}^{3}$

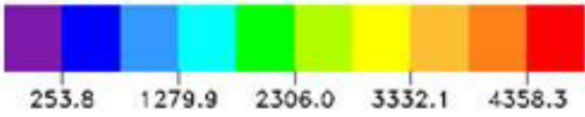

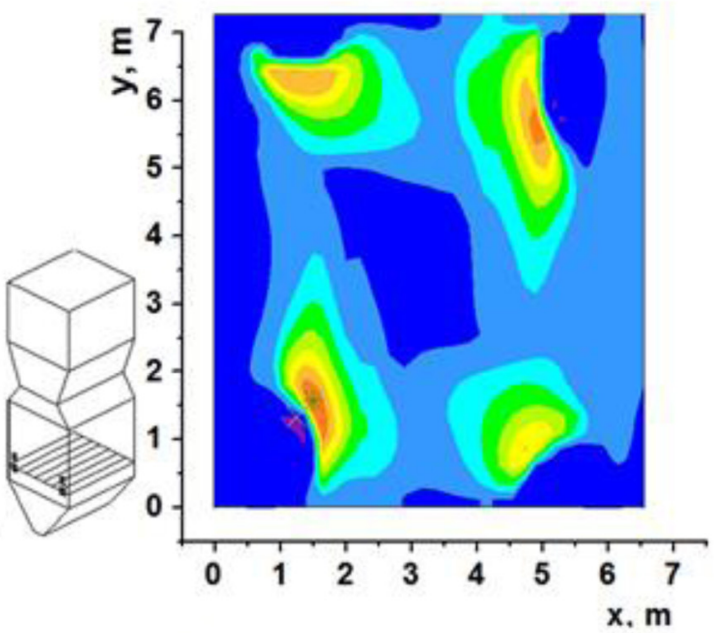

NO, $\mathrm{mg} / \mathrm{m}^{3}$

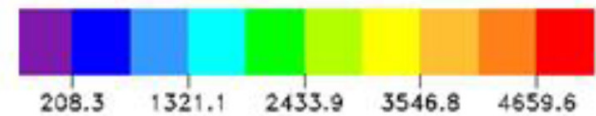

* Maximum 4400.1

Average1329.0 $*$ Maximum 4705.0

Average 1220.2

$\times$ Minimum $\quad 212.0$

$\times$ Minimum 162.8
a) Monodisperse flame
b) Polydisperse flame

Fig. 12. Distribution of concentration of nitrogen oxide in the cross-section of the combustion chamber camera $(z=4.81 \mathrm{~m})$ 
of nitrogen oxides from air nitrogen) [24]. At the height of $z=13.6 \mathrm{~m}$, where coal-dust flame temperature starts to decrease, this mechanism does not work, contribute to the formation of nitric oxide makes the fuel nitrogen. This is true both for combustion of polydisperse and monodisperse flame.

Fig. 10 shows the distribution curves of the concentration of nitric oxide. Here the experimental data obtained directly at Almaty TPP-3 are also presented. Average values for polydisperse flame at the outlet of the combustion chamber is $555 \mathrm{mg} / \mathrm{m}^{3}$, for monodisperse flame this value is $523 \mathrm{mg} / \mathrm{m}^{3}$ (under normal conditions). Values obtained as a result of field experiment are closer to the curve for a polydisperse NO flame.

The formation of nitric oxide and nitrogen-containing substances is ambiguous, complex, non-linear process that can occur for a variety of schemes and mechanisms. However, the analysis of results of computing experiment shows that they are in quite good agreement with the experimental data obtained on object of research (combustion chamber of boiler BKZ-160 Almaty TPP-3) [15]. It may be noted that the model of burning polydisperse flame better describes the real process of coal combustion in the combustion chamber.

\section{Conclusion}

In this paper, research of processes of turbulent heat and mass transfer in high-reacting flows is conducted and defined characteristics of concentration of oxygen $\mathrm{O}_{2}$, carbon oxides $\mathrm{CO}, \mathrm{CO}_{2}$, and nitrogen oxide NO in the real three-dimensional physical-chemical system (combustion chamber).

The study can be formulated following conclusions:

1. In the arrangement of burners, which is enriched with oxygen, chemical energy takes a maximum value, as the energy released by chemical reactions depends on the concentration of oxygen in the combustion chamber. Closer to the exit of the combustion chamber an oxygen concentration decreases because of it initially burnout, chemical processes weaken.

2. The nature of formation of carbon oxide and carbon dioxide is various. Maximum concentration of carbon monoxide reaches in the zone of active burning, the formation of carbon dioxide increases moving towards the exit from the furnace. This is due to afterburning of carbon monoxide $\mathrm{CO}$ in the upper combustion chamber with the additional formation of carbon dioxide $\mathrm{CO}_{2}$.

3. The formation of nitric oxide and nitrogen-containing substances is ambiguous, complex, non-linear process that can occur for a variety of schemes and mechanisms. The most intensive formation of nitrogen oxide NO occurs in the propagation of the burners flows, where a maximum volume of fuel and oxidant are present.

4. The results of computer simulation of temperature and nitric oxide were compared with the results of field experiments, the analysis of which confirms the correctness of the chosen model of the numerical experiment.

5. The nature of combustion of mono- and polydisperse dust is different. The effect of fineness has a significant impact on the processes of heat and mass transfer in the combustion chamber of TPP boilers. The model of burning of polydisperse dust reflects real process of burning more precisely that confirms comparison with field. However, the use of this model requires a large computer, time resources. 
6. The results obtained in this study will help to advice for optimization the process of combustion pulverized coal to reduce emissions. And will be helpful in the creation of power plants to "clean" and efficient use of coal.

\section{Acknowledgements}

Work is performed under the financing of the Ministry of Education and Science of the Republic of Kazakhstan Grant IRN's: AP05132988, AP05133590 and BR05236730. The last author, P. Šafařík, expresses thanks for support by the Project No. CZ.2.16/3.1.00/21569 Centre 3D Volumetric Anemometry.

\section{References}

[1] Alijarov, B. K., Alijarova, M.B., Combustion of Kazakh coals in thermal power stations and large-power boiler houses, Almaty, 2011. (in Russian)

[2] Askarova, A. S., Bekmukhamet, A., Bolegenova, S. A., Beketayeva, M. T., Maximov, V. Yu., Ospanova, Sh. S., Gabitova, Z. K., Numerical modeling of turbulence characteristics of burning process of the solid fuel in BKZ-420-140-7C combustion chamber, International Journal of Mechanics 8 (2014) 112-122.

[3] Askarova, A., Bekmukhamet, A., Bolegenova, S., Ospanova, Sh., Symbat, B., Maximov, V., Beketayeva, M., Yergaliyeva, A., 3-D modeling of heat and mass transfer during combustion of solid fuel in Bkz-420-140-7c combustion chamber of Kazakhstan, Applied Fluid Mechanics 9 (2) (2016) 699-709.

[4] Askarova, A. S., Bolegenova, S. A., Bekmuhamet, A., Maximov, V. Yu., Mathematical simulation of pulverized coal in combustion chamber, Procedia Engineering 42 (2012) 1259-1265.

[5] Askarova, A. S., Bolegenova, S. A., Bekmukhamet, A., Maximov, V. Yu., Beketayeva, M. T., Ospanova, Sh. S., Gabitova, Z. K., Investigation of turbulence characteristics of burning process of the solid fuel in BKZ 420 combustion chamber, WSEAS Transactions on Heat and Mass Transfer 9 (2014) 39-50.

[6] Askarova, A. S., Bolegenova, S. A., Bekmukhamet, A., Ospanova, Sh. S., Gabitova, Z., Using 3D modeling technology for investigation of conventional combustion mode of BKZ-420-140-7C combustion chamber, Engineering and Applied Sciences 9 (1) (2014) 24-28.

[7] Askarova, A. S., Bolegenova, S. A., Bolegenova, S., Bekmukhamet, A., Maximov, V. Yu., Beketayeva, M. T., Numerical experimenting of combustion in the real boiler of CHP, International Journal of Mechanics 7 (3) (2013) 343-352.

[8] Askarova, A. S., Bolegenova, S. A., Maximov, V. Yu., Bekmukhamet, A., Beketayeva, M. T., Gabitova, Z. K., Computational method for investigation of solid fuel combustion in combustion chambers of a heat power plant, High temperature 53 (5) (2015) 751-757.

[9] Askarova, A. S., Bolegenova, S. A., Maximov, V. Yu., Bekmukhamet, A., Ospanova, Sh. S., Numerical research of aerodynamic characteristics of combustion chamber BKZ-75 mining thermal power station, Procedia Engineering 42 (2012) 1250-1259.

https://doi.org/10.1016/j.proeng.2012.07.517

[10] Askarova, A.S., Karpenko, E.I., Karpenko, Yu.E., Messerle, V.E., Ustimenko, A. B., Mathematical modelling of the processes of solid fuel ignition and combustion at combustors of the power boilers, Proceedings of the 7th International Fall Seminar on Propellants, Explosives and Pyrotechnics, Xian, 2007, pp. 672-683.

[11] Askarova, A. S., Lavrichsheva, Ye. I., Leithner, R., Müller, H., Magda, A., Combustion of low-rank coals in furnaces of Kazakhstan coal-firing power plants, VDI Berichte 1088 (2007) 497-502. 
[12] Askarova, A. S., Messerle, V. E., Ustimenko, A. B., Bolegenova, S. A., Bolegenova, S. A., Maximov, V. Yu., Yergaliyeva, A.B., Reduction of noxious substance emissions at the pulverized fuel combustion in the combustor of the BKZ-160 boiler of the Almaty heat electropower station using the "Overfire Air" technology, Thermophysics and Aeromechanics 23 (1) (2016) 125-134.

[13] Askarova, A. S., Messerle, V.E., Ustimenko, A. B., Bolegenova, S. A., Maximov, V. Yu., Gabitova, Z. K., Numerical simulation of pulverized coal combustion in a power boiler furnace, High Temperature 53 (3) (2015) 445-452.

[14] Askarova, A. S., Safarik, P., Bolegenova, S. A., Maximov, V. Yu., Beketayeva, M. T., Numerical modeling of pulverized coal combustion at thermal power plant boilers, Thermal Science 24 (3) (2015) 275-282.

[15] Askarova, A. S., Safarik, P., Maximov, V. Yu., Bolegenova, S., Bolegenova, S., Yergaliyeva, A., Numerical investigation of heat and mass transfer processes in the combustion chamber of industrial power plant boiler. Part 1. Flow field, temperature distribution, chemical energy distribution, Applied and Computational Mechanics 11 (2017) 115-128. https://doi.org/10.24132/acm.2017.395

[16] Buchmann, M. A., Askarova, A., Structure of the flame of fluidized-bed burners and combustion processes of high-ash coal, Proceedings of the 18th Dutch-German Conference on Flames, VDI Berichte, 1997, pp. 241-244.

[17] Gorokhovski, M., Chtab-Desportes, A., Voloshina, I., Askarova, A., Stochastic simulation of the spray formation assisted by a high pressure, AIP Conference Proceedings, Xian, 2010, pp. 66-73.

[18] Heierle, E., Leithner, R., Mueller, H., Askarova, A. S., CFD code FLOREAN for industrial boilers simulations, WSEAS Transactions on Heat and Mass Transfer 4 (4) (2009) 98-107.

[19] Leithner, R., Numerical simulation. Computational fluid dynamics CFD, Braunschweig, 2006.

[20] Messerle, V. E., Askarova, A. S., Ustimenko, A. B., Maximov, V. Ju., Bolegenova, S. A., Numerical simulation of the coal combustion process initiated by a plasma source, Thermophysics and Aeromechanics 21 (6) (2014) 747-754.

[21] Messerle, V.E., Karpenko, E. I., Askarova, A. S., Plasma enhancement of combustion of solid fuels, High Energy Chemistry 40 (2) (2006) 111-118.

[22] Müller, H., Numerical calculation of three-dimensional turbulent flows in steam generators with heat transfer and chemical reactions using the SNCR method and coal combustion, Braunschweig, 1992. (in German)

[23] Vockrodt, S., Leithner, R., Schiller, A., Askarova, A., Buchman, M., Firing technique measures for increased efficiency and minimization of toxic emissions in Kazakh coal firing, Combustion and Incineration 1492 (1999) 93-97.

[24] Zeldovich, Y.B., The oxidation of nitrogen in combustion explosions, Acta Physicochimica U.S.S.R 21 (1946) 577-628. (in Russian)

[25] Zeldovich, Y. B., Sadovnikov, P. Y., Frank-Kameneckii, D. A., Oxidation of nitrogen in combustion, Transactions Academy of Sciences USSR, Moscow - Leningrad, 1947. (in Russian) 